the publication of Trick or Treatment? Alternative Medicine on Trial. ${ }^{2}$ But here the possibility of what might be learned from CAM about our ability to stimulate selfregulating and self-healing mechanisms whose pervasive role in medicine Ernst and Singh acknowledge, is tragically neglected. Dismissing the results of the Bristol Homeopathic Hospital clinical outcome study on the grounds of explanations other than the effect of homeopathic medicines (some of which are tendentious and don't reflect a diligent study of the research paper), they ignore the core fact that for whatever reason many patients with a long and continuing history of significant illness despite conventional treatment did remarkably well. ${ }^{3}$

The question is not 'do CAM treatments show efficacy in formal trials', but 'do they enhance patients' whole wellbeing and quality of life?' And if so how? And by what means can we make better use of whatever is the answer to 'how'? And what more can we learn about health, illness, and the human condition in the process? Surely this should be the agenda of an academic department of complementary medicine? Surely its original remit to investigate the scientific basis of CAM did not preclude this? Surely it was not merely to investigate whether CAM can be fitted into the same box as conventional medicine; made to fit the prevailing medical model?

To conclude, this book offers a salutary critique of the problems that beset the investigation and integration of CAM in relation to conventional medicine, but by a more genuinely truthful and truly scientific examination of its subject it could have enlarged our vision of health care. Unfortunately it only serves to perpetuate a kind of scientific tunnel vision.

\section{Jeremy Swayne}

\section{REFERENCES}

1. Healthwork UK. National Occupational Standards for Homeopathy. Bristol: Healthwork UK, 2000.

2. Godlee F. Reclaiming the placebo effect. $B M J 2008$; 336(3 May): doi:10.1136/bmj.39567.551181.47 http://www.bmj.com/cgi/content/full/336/7651/0?rss=1 (accessed 5 Sep 2008).

3. Spence DS, Thompson EA, Barron SJ. Homeopathic treatment for chronic disease: a 6-year, universityhospital outpatient observational study. Journal of Alternative and Complementary Medicine 2005; 11(5): 793-798.

DOI: 10.3399/bjgp08X342525

\section{EDZARD ERNST - A RESPONSE}

Trick or Treatment? Alternative Medicine on Trial is not a book against alternative medicine, it is a book in favour of good evidence and single standards in health care. Jeremy Swayne admits that 'truthfulness is an essential attribute' but criticizes our book for lack of 'wisdom and discernment', 'lack of ... balance', neglecting 'the positives' and disregarding 'the power and importance of non-specific and placebo effects'. He concludes by accusing us of 'scientific tunnel vision'. These are strong words which require a robust response.

Using our chapter on acupuncture as an example, we can effortlessly demonstrate that we bend over backwards to present the current evidence as balanced and truthfully as possible. We discuss the history and complexities of clinical trials and the best current scientific evidence in much detail. The truth is that, according to this evidence acupuncture might be effective for some types of pain and nausea. The truth is that even this evidence is not fully convincing (NICE recently recommended against using acupuncture for knee osteoarthritis, the flag-ship indication of acupuncturists!). ${ }^{1}$ The truth is that it is not free of risks. The truth is that it is expensive compared to many other effective treatments.

The truth we present is based on the best available evidence, which means that sometimes we endorse therapies (for example, several herbal treatments) and sometimes we have to be very critical about them (for example, magnet therapy). But Swayne does not appreciate this type of truth. Why? Presumably because, when our truth is applied to his pet therapy, homoeopathy, this form of treatment appears like a sick joke.

In his endeavor to promote his type of 'truth', Swayne wants us to discuss the failings and faults of conventional medicine. We do not deny that these exist. Maybe, one day, when we write a book about conventional medicine, we will discuss them in detail. But, writing about alternative medicine, we think it is fair to mention them only in passing.

And finally, Swayne points to the importance of the placebo effect. But so do we, even in much detail. The difference is that we try to apply just one standard while Swayne uses two. The placebo-effect is clearly powerful, thankfully we both agree on that. Swayne believes this justifies the routine use of homeopathy and other ineffective treatments. We point out that you don't need to administer a placebo to generate a placebo response - effective treatments do that too and they convey specific effects as well. The logical conclusion therefore is that, by using pure placebos, we do our patients a grave disservice.

So who is suffering from 'tunnel vision'? We suggest the readers of this debate go to their library, take out our book Trick or Treatment? Alternative Medicine on Trial and make up their own mind.

\section{Edzard Ernst}

\section{REFERENCE}

1. National Institute for Health and Clinical Excellence. Osteoarthritis NICE version - draft guidance for consultation. NICE: London, 2007.

http://www.nice.org.uk/guidance/index.jsp?action =d ownload\&o=35844 (accessed 9 Sep 2008). 